\title{
Extrato de própolis e seu efeito na conservação da maça Fuji (Malus domestica)
}

\author{
Extract of red propolis and its effect on the conservation of Fuji apple (Malus domestica) \\ Extracto de propóleo y su efecto sobre la conservación de la manzana Fuji (Malus domestica)
}

Recebido: 15/01/2021 | Revisado: 18/01/2021 |Aceito: 27/01/2021 | Publicado: 06/02/2021

\author{
Weverton Pereira de Medeiros \\ ORCID: https://orcid.org/0000-0001-9193-894X \\ Universidade Federal do Espirito Santos, Brasil \\ E-mail: weverton_cafu@hotmail.com.br \\ Alfredina dos Santos Araujo \\ ORCID: https://orcid.org/0000-0002-9336-7308 \\ Universidade Federal de Campina Grande, Brasil \\ E-mail: alfredina@ccta.ufcg.edu.br \\ Maria do Socorro Araujo Rodrigues \\ ORCID: https://orcid.org/0000-0002-1646-1624 \\ Universidade Federal de Campina Grande, Brasil \\ E-mail: fernandaa.rodrigues@hotmail.com \\ Maria Lucimar da Silva Medeiros \\ ORCID: https://orcid.org/0000-0002-7293-756X \\ Universidade estadual de Campinas, Brasil \\ E-mail: marialucimarmedeiros@gmail.com \\ Tiago da Nóbrega Albuquerque \\ ORCID: https://orcid.org/0000-0001-8046-8727 \\ Universidade Federal de Campina Grande, Brasil \\ E-mail: tiago.nobrega.pb@gmail.com \\ Morgana Aragão Araújo \\ ORCID: https://orcid.org/0000-0001-6727-2770 \\ Universidade Federal de Campina Grande, Brasil \\ E-mail: morganaaragao@ hotmail.com \\ Amanda Araujo Rodrigues \\ ORCID: https://orcid.org/0000-0002-0450-4631 \\ Universidade Federal de Campina Grande, Brasil \\ E-mail: rodriguesaaraujo10@gmail.com \\ Bárbara Bruna Maniçoba Pereira Medeiros \\ ORCID: https://orcid.org/0000-0003-4175-9892 \\ Universidade Federal de Campina Grande, Brasil \\ E-mail: bárbara.bmp@hotmail.com \\ Érik Serafim da Silva \\ ORCID: https://orcid.org/0000-0002-4224-4113 \\ Universidade Federal da Paraíba, Brasil. \\ E-mail: erik.silva@professor.pb.gov.br \\ Isaac Araújo Gomes \\ ORCID: https://orcid.org/0000-0001-7389-0014 \\ Universidade Federal do Espirito Santos, Brasil \\ E-mail: isaacbiomed1@gmail.com
}

\begin{abstract}
Resumo
Esse estudo buscou verificar a ação da própolis vermelha como revestimento comestível na conservação da maçã da cultivar "Fuji", utilizando temperaturas de $7^{\circ} \mathrm{C}$ (refrigerada) e $30^{\circ}$ (ambiente) e nas concentrações de própolis a $3 \%$ e $5 \%$, para a pesquisa, foi utilizado essa fruta por seu valor nutricional, rica pectina, tanino e flavonóides, que são fitonutrientes, que agem como antioxidantes e previnem diversas doenças. A solução filmogênica aplicada foi extrato de própolis vermelha, que possui substâncias que retardam o amadurecimento da cultivar, assim contribuindo para o aumento da sua vida útil. As amostras foram imergidas nas concentrações, em seguida postas em seus devidos ambientes, de onde eram retiradas a cada 5 dias, durante 30 dias, foram realizadas analises microbiológicas, que constatom a ausência de Salmonela ssp e Staphylococcus spp, e observou-se o retardo do desenvolvimento de fungos filamentosos, coliformes $35^{\circ}$ e coliformes $45^{\circ}$ até o $15^{\circ}$ dia para a concentração a $3 \%$, e 25 dias para a $5 \%$, confirmando a eficiência do revestimento contra o desenvolvimento de Microorganismo, Em relação a físico-química, as amostras apresentaram uma interação no ratio, contribuindo para o estado de maturação do fruto.
\end{abstract}

Palavra-chave: Malus; Conservação; Própolis vermelha. 


\begin{abstract}
This study sought to verify the action of red propolis as an edible coating in the conservation of the apple of the cultivar "Fuji", using temperatures of $7{ }^{\circ} \mathrm{C}$ (refrigerated) and $30^{\circ}$ (ambient) and in the concentrations of propolis at $3 \%$ and $5 \%$, for the research, this fruit was used for its nutritional value, rich pectin, tannin and flavonoids, which are phytonutrients, which act as antioxidants and prevent various diseases. The filmogenic solution applied was red propolis extract, which has substances that delay the ripening of the cultivar, thus contributing to the increase of its useful life. The samples were immersed in the concentrations, then placed in their proper environments, from where they were taken every 5 days, for 30 days, microbiological analyzes were carried out, which confirmed the absence of Salmonela ssp and Staphylococcus spp, and the delay of the development of filamentous fungi, coliforms $35^{\circ}$ and coliforms $45^{\circ}$ until the 15 th day for the concentration at $3 \%$, and 25 days for the $5 \%$, confirming the efficiency of the coating against the development of Microorganism, In relation to physical-chemical, the samples showed an interaction in the ratio, contributing to the ripeness of the fruit.
\end{abstract}

Keywords: Malus; Conservation; Própolis.

\title{
Resumen
}

Este estudio buscó verificar la acción del propóleo rojo como recubrimiento comestible en la conservación de la manzana del cultivar "Fuji", utilizando temperaturas de $7^{\circ} \mathrm{C}$ (refrigerada) y $30^{\circ}$ (ambiente) y en las concentraciones de propóleo al 3\% y 5\%, para En la investigación, esta fruta fue utilizada por su valor nutricional, rico en pectina, tanino y flavonoides, que son fitonutrientes, que actúan como antioxidantes y previenen diversas enfermedades. La solución filmógena aplicada fue el extracto de propóleo rojo, el cual posee sustancias que retrasan la maduración del cultivar, contribuyendo así al aumento de su vida útil. Las muestras se sumergieron en las concentraciones, luego se colocaron en sus ambientes adecuados, de donde se tomaron cada 5 días, durante 30 días se realizaron análisis microbiológicos, los cuales confirmaron la ausencia de Salmonela ssp y Staphylococcus spp, y se observó el retraso. del desarrollo de hongos filamentosos, coliformes $35^{\circ}$ y coliformes $45^{\circ}$ hasta el día 15 para la concentración al 3\%, y a los 25 días para el 5\%, confirmando la eficiencia del recubrimiento frente al desarrollo de Microorganismos, en relación a los efectos físico-químicos, las muestras mostraron una interacción en la proporción, contribuyendo a la madurez del fruto.

Palabras-clave: Malus; Conservación; Propóleo rojo.

\section{Introdução}

Ao longo dos anos e dos avanços tecnológicos, se fez necessário cada vez mais a busca de alternativas na conservação de alimentos que possam, além de aumentar sua vida útil de prateleira, agregar características ao produto, que seja viável de forma ambiental e econômica. Com isso enfatizou os estudos com a utilização da própolis como revestimento comestível, utilizando suas características antioxidantes, antibactericida e antifúngica para conservar os frutos e hortaliças.

Revestimento comestível é uma camada preparada a partir de determinados tipos de materiais biológicos, que age como uma ferramenta de proteção, evitando danos físicos e biológicos e elevando o tempo de vida útil dos alimentos, como maçãs (Henrique, Cereda, \& Sarmento, 2008). O uso desse revestimento atribui diversas características ao produto, podendo ser físicas, químicas, microbiológicas e sensoriais.

O uso dessa embalagem traz grandes vantagens por apresentar um polímero natural em sua composição (Davanço, Tanada-Palmu, \& Grosso, 2007). Possui um custo de produção satisfatório e não tóxico. que influência de forma positiva, diretamente na aparência do produto submetido ao revestimento (Oliveira \& Nunes, 2011).

O revestimento apresenta diversas funções como barreira, evitando a troca gasosa $(\mathrm{CO} 2$ e $\mathrm{O} 2)$ e consequentemente a perda de umidade, diminuição da respiração do fruto, melhorando a aparência intrínsecas do fruto coberto pela solução (Sanchez-Gonzalezcháfer, Hernández, Chiralt, \& González-Martínez, 2011).

O número de pesquisas sobre a própolis como filmes poliméricos são reduzidos ainda e as pesquisas realizadas usualmente sem fins alimentícios (Pastor, Sánchez-González, Cháfer, \& González- Martínez, 2010). Os flavonóides são compostos fenólicos e principais agentes biológicos ativos da própolis (Cabral, Oldoni, Prado, Bezerra, \& Alencar, 2009), no entanto podemos encontrar em sua composição diversas substâncias, entre elas as ceras, óleos essenciais, pólen e vários componentes orgânicos como ferro e zinco, vitaminas (B1, B2, B3 e B6), ácido benzóico, éster, cetonas, lactonas, quinona, 
esteróides e açúcares e ainda pigmentos naturais como clorofilas e carotenóides.

Sendo assim, o objetivo deste trabalho foi avaliar o efeito do revestimento a base de extrato de própolis vermelha em maçãs do tipo Fuji armazenadas a temperatura ambiente controlada e refrigerada durante 30 dias para um melhor detalhamento durante o período de conservação.

\section{Materiais e Métodos}

A própolis utilizada na pesquisa foi adquirida na cidade de João Pessoa-PB, no apiário EDIMEL, os frutos foram adquiridos no mercado público na cidade de Pombal-PB e as análises foram realizadas no centro vocacional tecnológico (CVT).

Recebimento e seleção das amostras: As maçãs foram transportadas e armazenadas de forma adequada até os laboratórios (CVT) no município de Pombal, foram selecionados 150 frutos, de acordo com estádio de maturação, estando os mesmo e livres de danos físicos e injurias que pudessem vim a apresentar qualquer comprometimento do mesmo.

Sanitização das amostras: Os frutos foram pré-lavados em água corrente, em seguida foram selecionados e sanitizados em solução de hipoclorito de sódio a $200 \mathrm{mg} / \mathrm{L}$.

Elaboração do extrato alcoólico: O extrato foi elaborado seguindo a descrição da metodologia de Daugsch (2007), com algumas modificações.

Elaboração dos revestimentos: O revestimento foi elaborado seguindo a metodologia Santos (2007), descrito na Tabela 1, com algumas modificações.

Tabela 1 - Formulações dos revestimentos de acordo com a aplicabilidade da própolis vermelha.

\begin{tabular}{cc}
\hline & Formulações dos revestimentos \\
Formulação 1 & Formulação 2 \\
$0,7 \mathrm{~g}$ glicerina & $0,7 \mathrm{~g}$ glicerina \\
$1,7 \mathrm{~g}$ Açúcar invertido & $1,7 \mathrm{~g}$ Açúcar invertido \\
$4 \mathrm{~g}$ amido de milho & $4 \mathrm{~g}$ amido de milho \\
$100 \mathrm{~mL}$ Agua & $100 \mathrm{~mL}$ Agua \\
$3 \mathrm{~mL}$ extrato de Própolis vermelha & $5 \mathrm{~mL}$ extrato de Própolis vermelha \\
\hline
\end{tabular}

Fonte: Autores.

Aplicação do revestimento (método do próprio): As amostras foram mergulhadas nas soluções filmogênicas, em seguida foram colocadas para secar em grades, sob a temperatura ambiente, sendo posterior identificadas e colocadas em bandejas de isopor.

Armazenamento: Foram armazenadas em geladeiras de temperatura controlada (BDO) sob temperaturas de $7^{\circ} \mathrm{Ce}$ $30^{\circ} \mathrm{C}$. Para comparações em cada ambiente tinha as amostras controle, sem revestimento.

\section{Caracterização dos biofilmes e dos frutos}

Caracterização microbiológica: a análises para Coliformes à $35^{\circ} \mathrm{C}$, Coliformes à $45^{\circ} \mathrm{C}$, Fungos filamentosos e leveduras, Salmonella sp e Staphylococcus spp., seguindo a metodologia descrita por APHA (2001). As cultivares da maçã do tipo "Fuji" foram submetidas ao armazenamento durante um período de 30 dias, sendo realizadas análises a cada 5 dias.

Caracterização físico-química: análises de $\mathrm{pH}$, acidez, vitamina $\mathrm{C}$, teor de umidade, cinzas, teor de carotenóides, sólidos solúveis totais (Brix), de acordo com a metodologia do Instituto Adolf Lutz (2008). 


\section{Resultados e discussões}

\subsection{Condições microbiológicas por tempo de armazenamento}

A Agência Nacional de Vigilância Sanitária - ANVISA por meio da resolução nº 12, de 2 de janeiro de 2001 (Brasil, 2001) estabelece para frutos, produtos originados de frutos e similares, a ausência de Salmonella sp para cada 25g do produto e presença de coliformes a $45^{\circ} \mathrm{C}$ de até $2 \times 10^{3} \mathrm{NMP} / \mathrm{g}$, sendo o referido grupo representado pela Escherichia coli.

A ANVISA não estabelece limites em relação a fungos filamentosos e Staphylococcus spp., porém foram realizadas essas análises para que pudesse ter uma avaliação.

De modo que, para avaliar as condições higiênico-sanitárias da matéria prima, foram realizadas análises para presença de Salmonella, onde constatou-se a ausência desse patogênico em todos os tempos, revestimentos e temperatura, concluindo que o produto permaneceu durante os 30 dias sobre os parâmetros de aceitação pela ANVISA.

Para a análise de Staphylococcus spp., em 100\% das amostras houve a ausência desse microorganismo, o que confirma que os frutos foram bem sanitizados e permaneceram sem contaminação durante todo o tempo de análise, mesmo sendo submetido a manipulação humana, De acordo com a International Commission of Microbiological Specifications for Foods - ICMSF (1978) e Leitão (1981), devem ser realizadas essas análises para verificar as condições ambiente nas quais os experimentos estão sendo realizados.

A Figura 1 apresenta os resultados para o crescimento de fungos filamentosos e leveduras em maçãs com e sem a aplicação de revestimentos durante o armazenamento a temperatura refrigerada e a temperatura ambiente.

Para os frutos mantidos a $7^{\circ} \mathrm{C}$, retardou em 10 dias para os frutos sem e com recobrimento, respectivamente, mostrando que a utilização dos revestimentos retardou 10 dias a atividade microbiana, mostrando a eficiência para este parâmetro.

Observa-se para a condição de temperatura 2 (Figura 1b) que as maçãs sem recobrimento apresentaram crescimento acentuado de fungos filamentosos e leveduras no controle do $5^{\circ}$ ao $10^{\circ}$ dia de armazenamento, porém segundo Lee et al. (2003) e Rojas - Graü, et al. (2007b), pode-se considerar uma carga microbiana de até $10^{6} \mathrm{UFC} / \mathrm{g}$ aceitável, já uma população acima desse valor pode causar problemas no aroma e sabor do produto.

Figura 1 - Crescimento de fungos filamentosos e leveduras em maçãs com e sem revestimento contendo a própolis durante o armazenamento a temperatura refrigerada (a) e a temperatura ambiente (b).
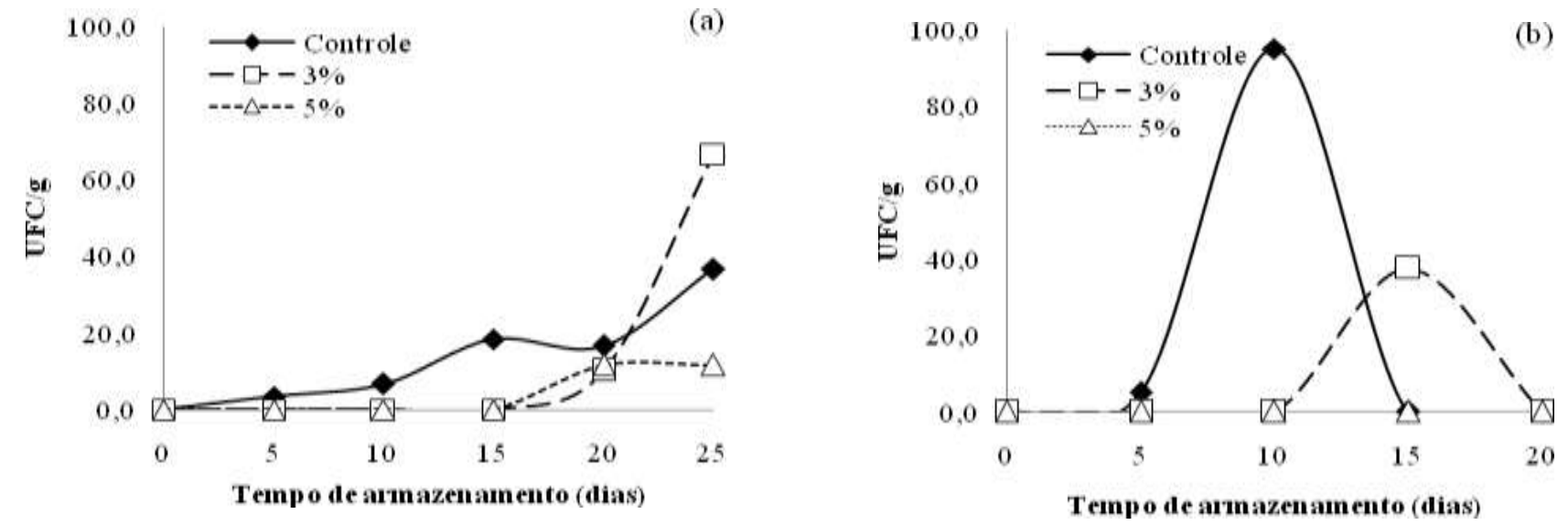

Fonte: Autores. 
A Figura 2 apresenta os resultados para as análises de coliformes a $35^{\circ} \mathrm{C}$ em maçãs com e sem a aplicação de revestimentos durante o armazenamento as temperaturas de $7^{\circ} \mathrm{C}$ e $30^{\circ} \mathrm{C}$.

Houve o desenvolvimento de coliformes a $35^{\circ} \mathrm{C}$ (Figura 2) nas maçãs do tratamento controle após o $5^{\circ}$ dia de armazenamento, onde foram registradas contagens de $93 \mathrm{NMP} / \mathrm{g}$ e $240 \mathrm{NMP} / \mathrm{g}$ no $20^{\circ}$ dia para as temperaturas de $7^{\circ} \mathrm{C}$ e $30^{\circ} \mathrm{C}$, simultaneamente. As maçãs que receberam aplicação de revestimentos contendo extrato de própolis (3\% e 5\%) não apresentaram o desenvolvimento de bactérias desse grupo até o $20^{\circ}$ dia de armazenamento, sendo a amostra com aplicação de $5 \%$ de extrato de própolis vermelha a mais eficiente para ambas temperaturas, apresentando-se constante, sem crescimento microbiano, indicando que nessas condições ambos os percentuais testados foram eficientes.

Figura 2 - Número Mais Provável (NMP/g) de coliformes a $35^{\circ} \mathrm{C}$ em maçãs com e sem a aplicação de revestimentos durante o armazenamento a temperatura refrigerada (a) e a temperatura ambiente (b).
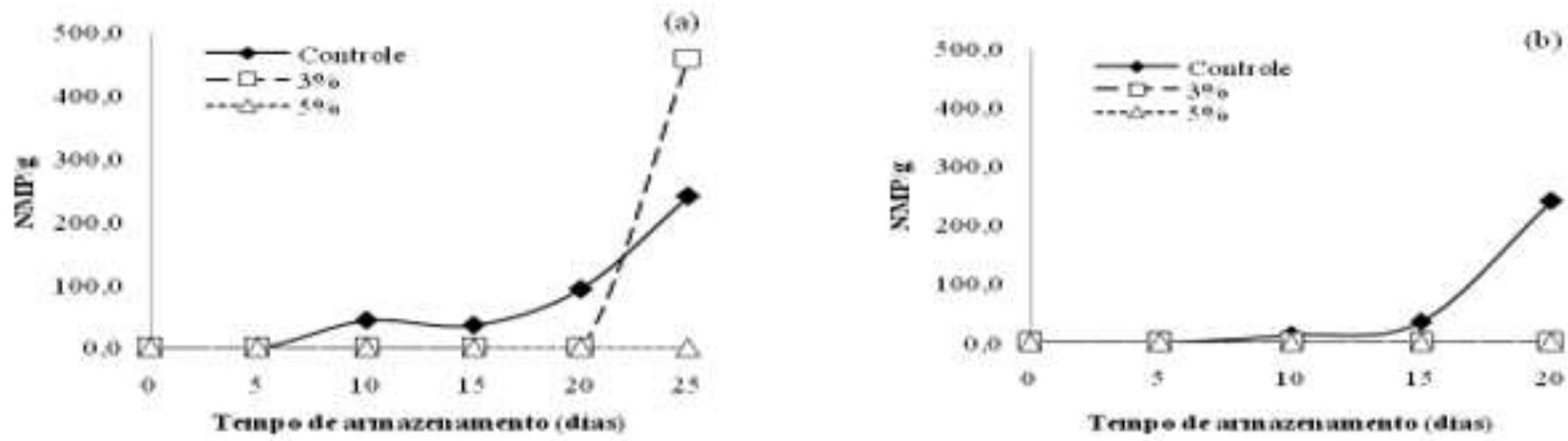

Fonte: Autores.

A Figura 3 apresenta os resultados para as análises de coliformes a $45^{\circ} \mathrm{C}$ em maçãs com e sem a aplicação de revestimentos durante o armazenamento as temperaturas de $7^{\circ} \mathrm{C}$ e $30^{\circ} \mathrm{C}$.

Conforme apresentado na Figura 3, em ambas as condições de temperatura estudadas, houve o desenvolvimento (240 $\mathrm{NMP} / \mathrm{g}$ ) de Coliformes a $45^{\circ} \mathrm{C}$ a partir do $15^{\circ}$ dia de armazenamento em maçãs que não receberam a aplicação dos revestimentos. O revestimento adicionado de 3\% de extrato de própolis retardou o desenvolvimento dessas bactérias, o qual se iniciou após o $20^{\circ}$ dia nas maçãs refrigeradas, e reduziu em $61,25 \%$ a contagem ao $25^{\circ}$ dia quando comparado às maçãs não revestidas. A adição de $5 \%$ do extrato foi eficiente para evitar o crescimento durante o período de armazenamento para ambas as amostras. 
Figura 3 - Número Mais Provável (NMP/g) de coliformes a $45^{\circ} \mathrm{C}$ em maçãs com e sem a aplicação de revestimentos durante o armazenamento a temperatura refrigerada (a) e a temperatura ambiente (b).

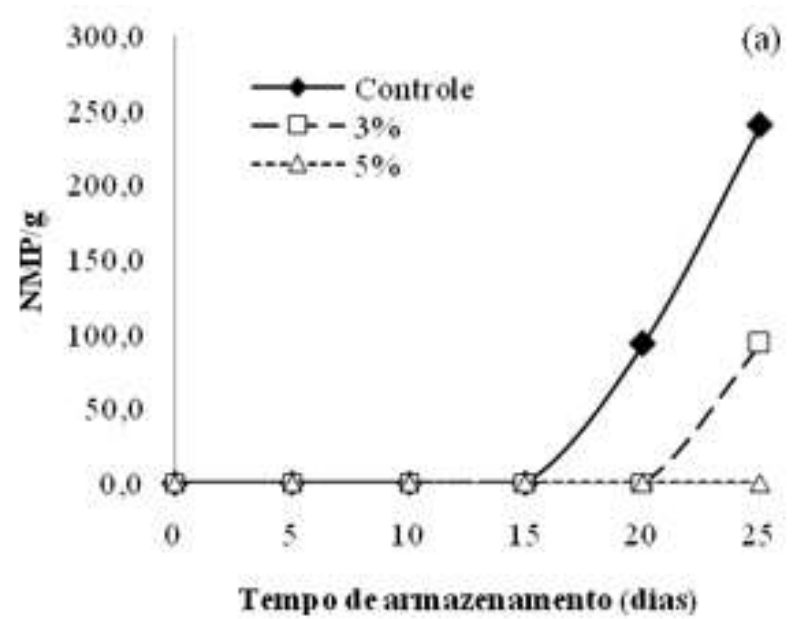

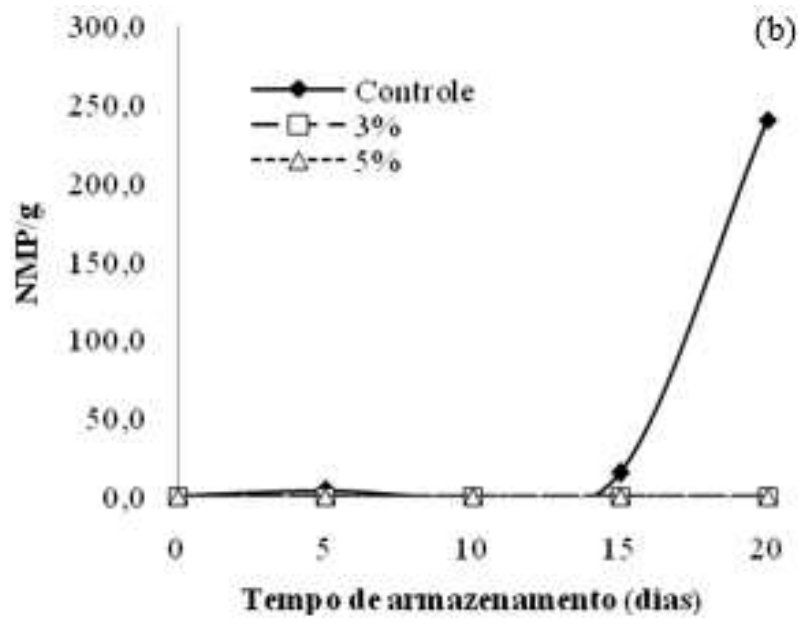

Fonte: Autores.

\subsection{Análises físico-químicas}

A Tabela 2 apresenta um resumo da análise de variância para pH, Sólidos solúveis (SS), Acidez Titulável (AT), Ratio (SS/AT), Teor de água e cinzas durante o armazenamento a $7^{\circ} \mathrm{C}$.

A partir da análise de variância apresentada na Tabela 2, para maçãs acondicionadas a $7^{\circ} \mathrm{C}$, verifica-se que houve interação significativa entre os fatores revestimento e tempo de armazenamento para o $\mathrm{pH}$, teor de sólidos solúveis, acidez titulável e ratio, ao nível de 5\% de probabilidade pelo teste $\mathrm{F}$, indicando que há uma dependência entre os efeitos dos revestimentos e do tempo de armazenamento sobre as características dessas variáveis. A aplicação dos revestimentos não apresentou efeito significativo no teor de água e vitamina $\mathrm{C}$, contudo foi evidenciada a influência isolada do fator tempo sobre essa variável.

Tabela 2 - Resumo da análise de variância para pH, Sólidos solúveis (SS), Acidez Titulável (AT), Ratio (SS/AT), Teor de água e cinzas durante o armazenamento a $7^{\circ} \mathrm{C}$.

\begin{tabular}{|c|c|c|c|c|c|c|c|}
\hline \multirow{2}{*}{$\mathrm{FV}$} & \multicolumn{4}{|c|}{ QM } & \multirow[b]{2}{*}{ Ratio } & \multirow[b]{2}{*}{$\begin{array}{l}\text { Teor de } \\
\text { água }\end{array}$} & \multirow[b]{2}{*}{ Vitamina C } \\
\hline & & $\mathrm{pH}$ & $\begin{array}{l}\text { Sólidos } \\
\text { solúveis }\end{array}$ & $\begin{array}{l}\text { Acidez } \\
\text { titulável }\end{array}$ & & & \\
\hline Revestimento (R) & 2 & $0,1319 * *$ & $0,1596 * *$ & $0,3694 * *$ & $1,7450^{*}$ & $4,8441^{\mathrm{ns}}$ & $0,2203^{\mathrm{ns}}$ \\
\hline Tempo (T) & 5 & $0,4379 * *$ & $1,2544 * *$ & $1,2126 * *$ & $12,3358 * *$ & $21,7667 * *$ & * $150,2132 * *$ \\
\hline Interação R x T & 10 & $0,0542 * *$ & $2,2022 * *$ & $0,1229 *$ & $4,0833 * *$ & $1,9783^{\mathrm{ns}}$ & $2,5278^{\mathrm{ns}}$ \\
\hline $\mathrm{CV}(\%)$ & - & 3,47 & 2,70 & 12,98 & 15,79 & 1,45 & 7,91 \\
\hline
\end{tabular}

$\mathrm{ns}, * *, *$ respectivamente não significativos, significativo a $\mathrm{p}<0,01$ e $\mathrm{p}<0,05$. Fonte: Autores.

A Tabela 3 apresenta um resumo da análise de variância para pH, Sólidos solúveis (SS), Acidez Titulável (AT), Ratio (SS/AT), Teor de água e cinzas durante o armazenamento a $30^{\circ} \mathrm{C}$.

Observa-se na Tabela 3, que houve interação significativa entre os fatores estudados para o teor de sólidos solúveis, acidez e ratio, todavia, houve efeito isolado do fator tempo sobre o pH, teor de água e Vitamina $\mathrm{C}$ para as maçãs mantidas a temperatura de $30^{\circ} \mathrm{C}$. 
Tabela 3. Resumo da análise de variância para pH, Sólidos solúveis (SS), Acidez Titulável (AT), Ratio (SS/AT), Teor de água e cinzas durante o armazenamento a $30^{\circ} \mathrm{C}$.

\begin{tabular}{lccccccc}
\multirow{2}{*}{ FV } & \multicolumn{7}{c}{ QM } \\
\cline { 2 - 7 } & GL & pH & $\begin{array}{c}\text { Sólidos } \\
\text { solúveis }\end{array}$ & $\begin{array}{c}\text { Acidez } \\
\text { titulável }\end{array}$ & Ratio & $\begin{array}{c}\text { Teor de } \\
\text { água }\end{array}$ & Vitamina C \\
\hline Revestimento & 2 & $0,0002^{\text {ns }}$ & $1,8428^{* *}$ & $0,1614^{* *}$ & $0,2511^{\text {ns }}$ & $2,9197^{\text {ns }}$ & $5,5869^{\text {ns }}$ \\
(R) & 4 & $0,1130^{* *}$ & $3,6219^{* *}$ & $0,4400^{* *}$ & $3,9545^{* *}$ & $9,1710^{* *}$ & $170,4595^{* *}$ \\
Tempo (T) & 8 & $0,0218^{\mathrm{ns}}$ & $0,6496^{* *}$ & $0,3458^{* *}$ & $2,8206^{* *}$ & $1,2164^{\mathrm{ns}}$ & $2,6380^{\mathrm{ns}}$ \\
Interação R x T & - & 2,72 & 6,38 & 9,82 & 13,89 & 1,51 & 9,69 \\
CV (\%) & - & &
\end{tabular}

$\mathrm{ns}, * *, *$ respectivamente não significativos, significativo a $\mathrm{p}<0,01 \mathrm{e} \mathrm{p}<0,05$. Fonte: Autores.

A Figura 4 apresenta o comportamento do pH de maçãs com e sem a aplicação de revestimentos durante o armazenamento a $7^{\circ} \mathrm{C}$ e $30^{\circ} \mathrm{C}$. Para a condição de temperatura 1 (a), essa variável foi influenciada pela aplicação do revestimento, havendo um aumento até o $15^{\circ}$ dia e em seguida uma redução, resultado ao $25^{\circ}$ dia de armazenamento em $\mathrm{pH}$ de3,86, 3,46 e 3,27 para os tratamentos controle, 3\% e 5\% de extrato de própolis, respectivamente. Para acondição de temperatura 2 (b), houve apenas a influencia do fator tempo, observou-se o maior valor ao $10^{\circ}$ dia e o $\mathrm{pH}$ final foi de 4,12 .

Figura 4 - pH de maçãs com e sem a aplicação de revestimentos durante o armazenamento a temperatura refrigerada (a) e a temperatura ambiente (b).
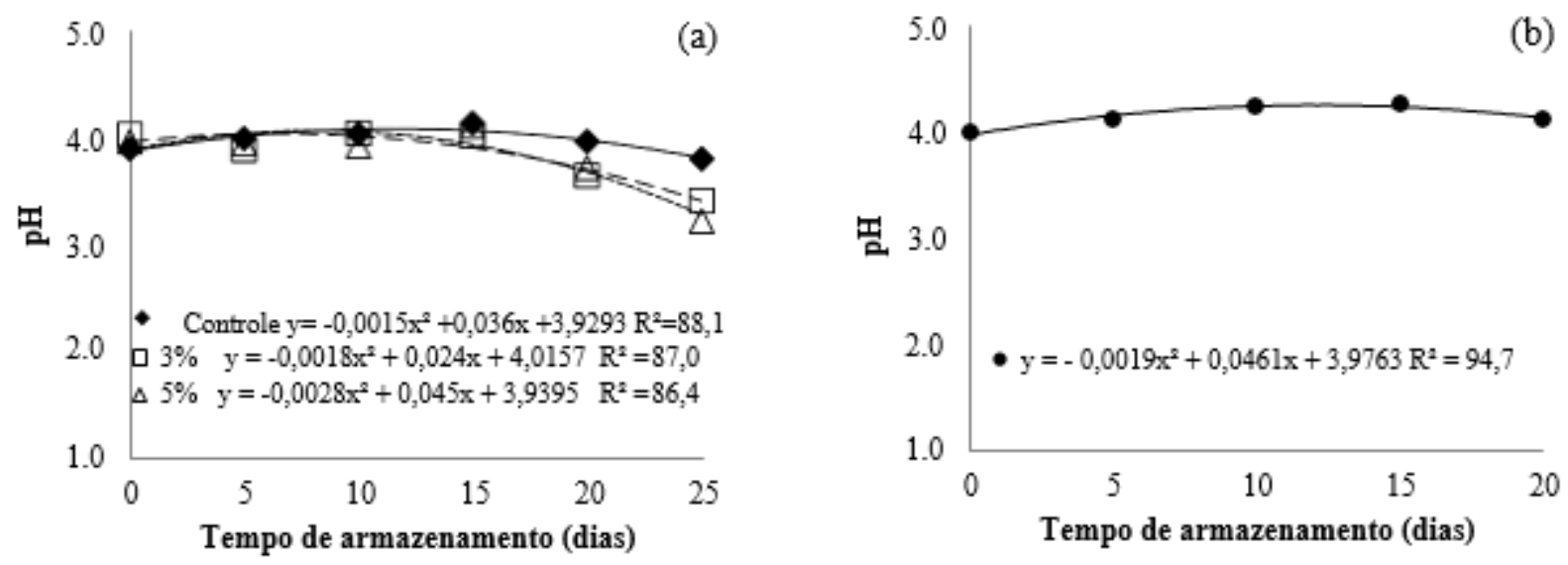

Fonte: Autores.

A Figura 5 apresenta o comportamento do teor de sólidos solúveis de maçãs com e sem a aplicação de revestimentos durante o armazenamento a $7^{\circ} \mathrm{C}$ e $30^{\circ} \mathrm{C}$.

Os teores de sólidos solúveis (Figura 5) nos frutos não revestidos apresentaram comportamento similar para ambas as temperaturas, no entanto a refrigeração possibilitou um acréscimo mais acentuado nos últimos dias, possivelmente devido ao maior tempo de armazenamento. Verifica-se para as maçãs mantidas a $7^{\circ} \mathrm{C}$ que a aplicação dos revestimentos provocou no $25^{\circ}$ dia um decréscimo no teor de sólidos de 15,89 e 13,04\%, respectivamente, para o filme com 3 e $5 \%$ de extrato de própolis. Comportamento contrário foi observado para a temperatura de $30^{\circ} \mathrm{C}$, que proporcionou um acréscimo acentuado ao término do armazenamento, sendo este de 54,35\% (Revestimento 3\%) e 24,28\% (Revestimento 5\%), o que indica a evolução do amadurecimento dos frutos nesta condição de armazenamento (Assis, 2011). 
Figura 5 - Teor de sólidos solúveis de maçãs com e sem a aplicação de revestimentos durante o armazenamento a temperatura refrigerada (a) e a temperatura ambiente (b).
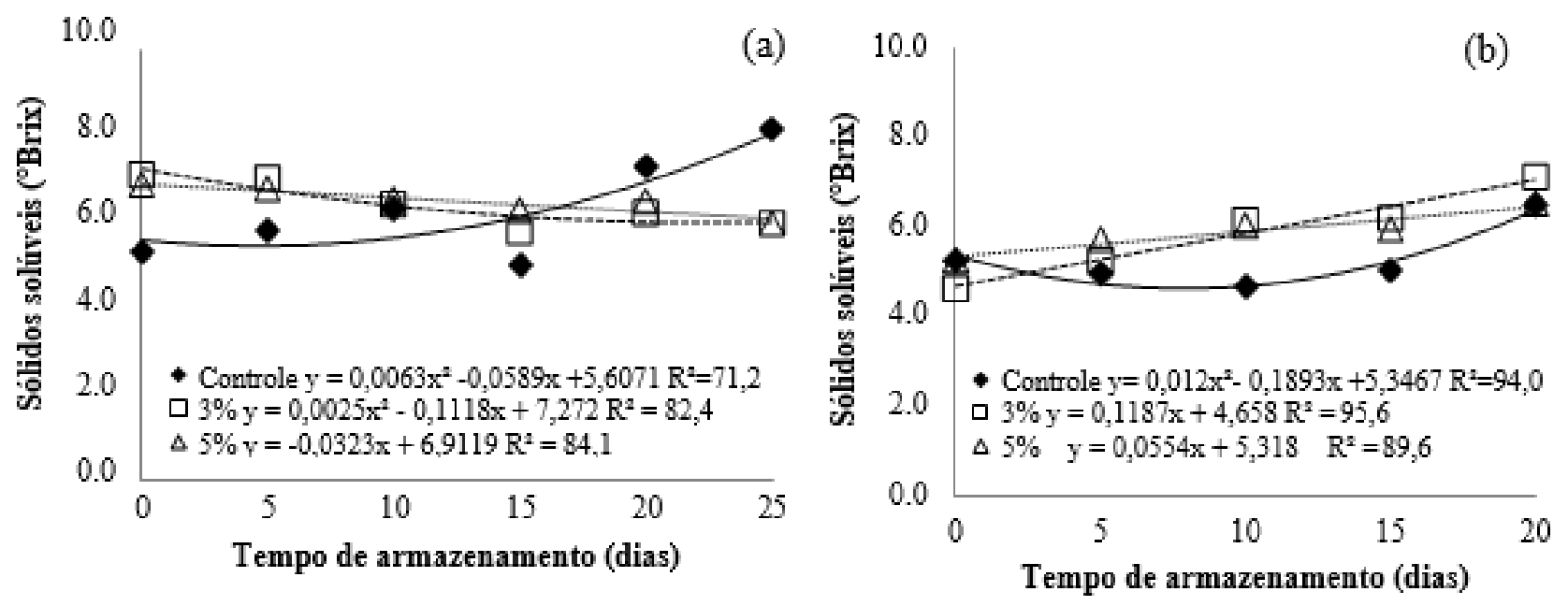

Fonte: Autores.

A Figura 6 apresenta os resultados para as análises de Acidez titulável (g de ácido málico/100g) de maçãs com e sem a aplicação de revestimentos durante o armazenamento a $7^{\circ} \mathrm{C}$ e $30^{\circ} \mathrm{C}$.

Conforme apresentado na Figura 6, as maçãs sem revestimento apresentaram teores de acidez similares para ambas às temperaturas, sendo os maiores registrados no $10^{\circ}$ dia de armazenamento. $\mathrm{O}$ revestimento contendo maiores percentuais de extrato de própolis proporcionou maiores teores de acidez para os frutos refrigerados (Figura 6a), onde ao $10^{\circ}$ dia de armazenamento foi registrado o maior percentual de ácido málico, sendo este de 0,18\%. Já para os frutos mantidos a temperatura de $30^{\circ} \mathrm{C}$ (Figura 6b), não houve diferenciação entre os percentuais de extrato de própolis na composição dos filmes. O decréscimo da quantidade de ácidos nas maçãs é decorrente da atividade metabólica ocasionada pela respiração dos frutos, conforme mencionado por Assis (2011). 
Figura 6 - Acidez titulável (g de ácido málico/100g) de maçãs com e sem a aplicação de revestimentos durante o armazenamento a temperatura refrigerada (a) e a temperatura ambiente (b).
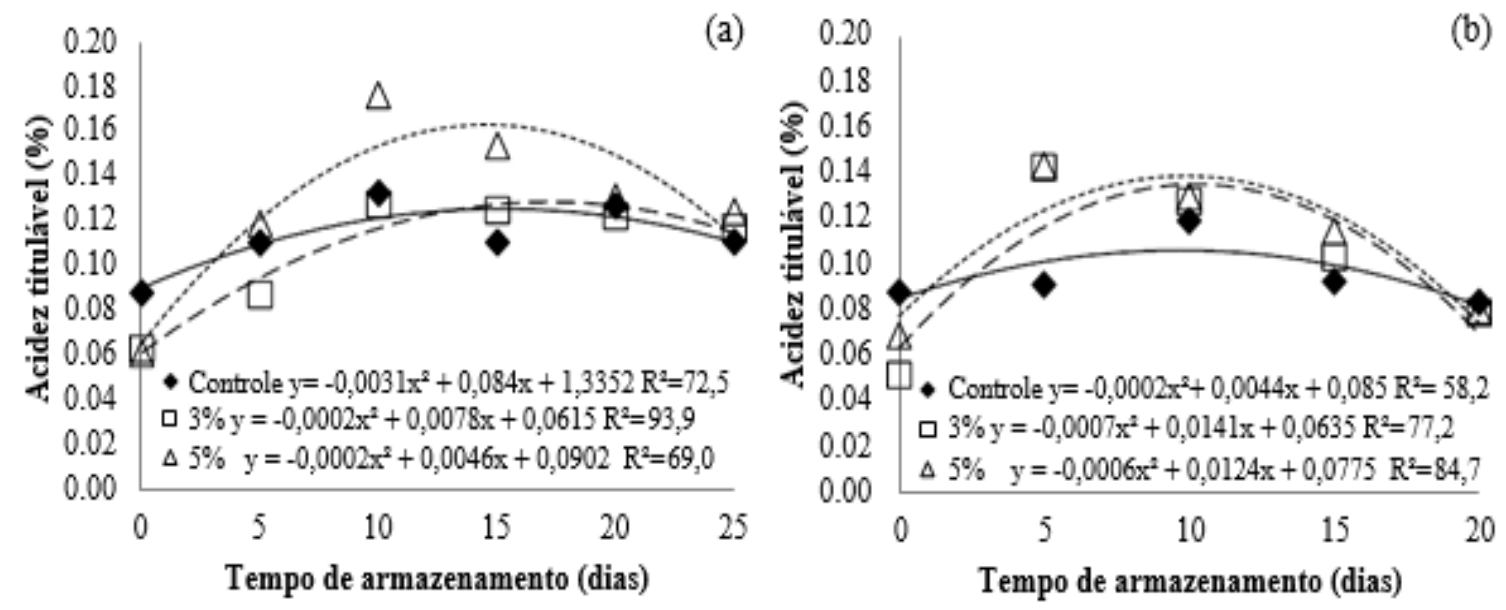

Fonte: Autores.

A Figura 7 apresenta os resultados para o Ratio (SS/AT) de maçãs com e sem a aplicação de revestimentos durante o armazenamento a $7^{\circ} \mathrm{C}$ e $30^{\circ} \mathrm{C}$.

Verifica-se na Figura 7, que o Ratio para ambas temperaturas de armazenamento, a amostra controle teve um crescimento com o tempo de armazenamento, sendo um fator positivo para o fruto em questão, pois é uma forma de grande relevância na avaliação do sabor dos frutos onde, esta característica é de fundamental importância para consumo in natura como para indústria, a qual ocorre, em grande parte, devido ao balanço de ácidos e açúcares, sendo mais representativo que a mensuração destes parâmetros isoladamente (Batista et al., 2013).

As amostras de 3\% e 5\% para ambas as faixas de temperatura de armazenamento, apresentaram-se com o mesmo comportamento da curva, todavia, as amostras para a temperatura de refrigeração, caracterizaram-se com desacelaramento da reação, retardando assim o efeito (SST/AT), entre $20^{\circ}$ e $25^{\circ}$ dia de armazenamento, podendo ser justificável pelo o efeito do revestimento assim como o efeito da baixa temperatura, diferentemente das amostras a temperatura ambiente.

Desta forma, quando os valores encontrados a partir desta relação são altos, significa que o fruto está em bom grau de maturação, pois quando há um elevado aumento nesse grau ocorre um decréscimo na acidez e alto conteúdo de SST, decorrentes da maturidade, onde quanto maior o resultado, mais saboroso tende a ser o fruto devido o equilíbrio açúcar/ácido (Souza \& Cól, 2014). 
Figura 7 - Ratio (SS/AT) de maçãs com e sem a aplicação de revestimentos durante o armazenamento a temperatura refrigerada (a) e a temperatura ambiente (b).

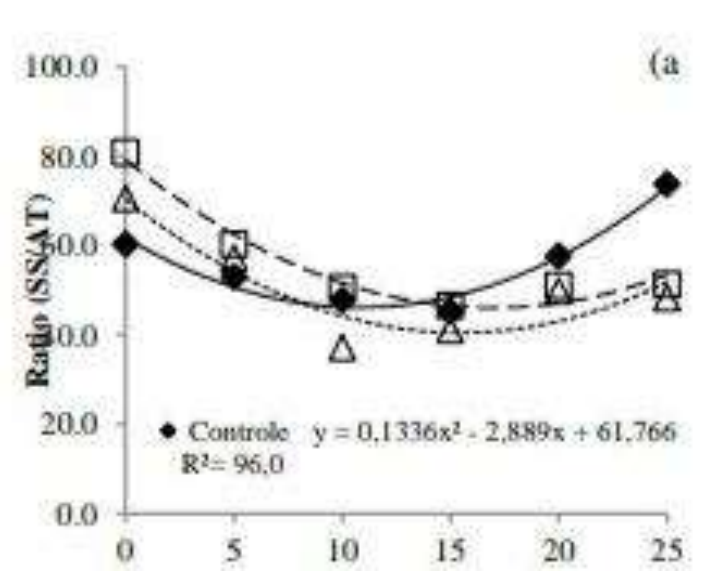

Tempo de armazenamento (dias)

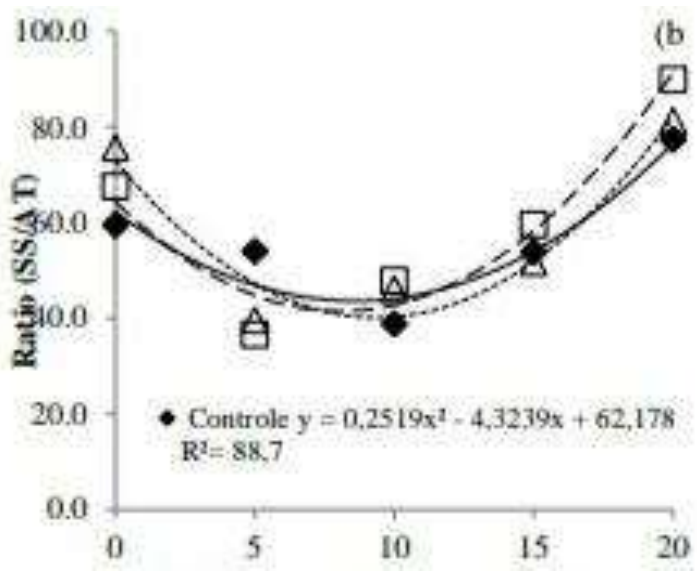

Tempo de armazenamento (dias)

Fonte: Autores.

Figura 8 apresenta os resultados para o teor de água $(\%)$ de maçãs com e sem a aplicação de revestimentos durante o armazenamento a $7^{\circ} \mathrm{C}$ e $30^{\circ} \mathrm{C}$.

O teor de água dos frutos em estudo não sofreu influência significativa $(\mathrm{p}<0,05)$ em função da aplicação dos revestimentos. Verifica-se na Figura 8 que para ambas as condições de temperatura estudadas, o teor de água das maçãs apresentou comportamento linear e foi reduzido ao longo do período de armazenamento, resultando em uma perda de 4,77 e $2,96 \%$ de água para a temperatura de $7^{\circ} \mathrm{C}$ e de $30^{\circ} \mathrm{C}$, simultaneamente.

Figura 8 - Teor de água (\%) de maçãs com e sem a aplicação de revestimentos durante o armazenamento a temperatura refrigerada (a) e a temperatura ambiente (b).
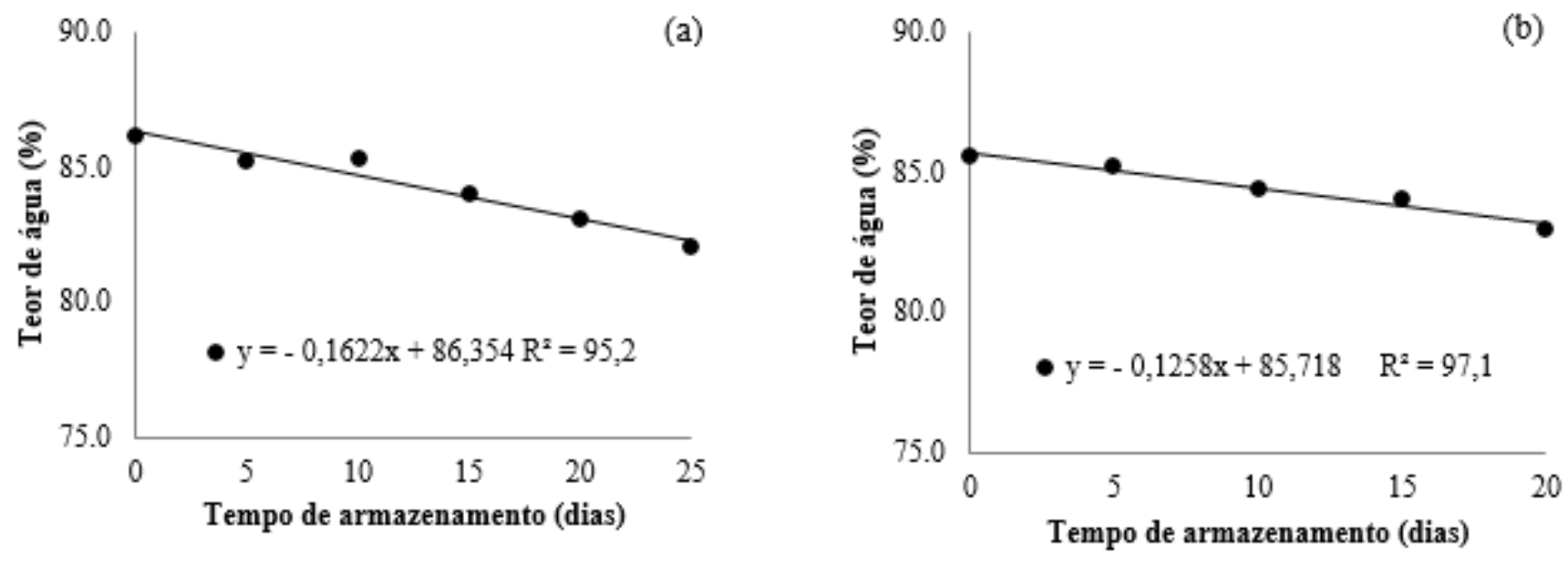

Fonte: Autores. 
A Figura 9 apresenta os resultados para o Teor de Vitamina C (mg/100g) de maçãs com e sem a aplicação de revestimentos durante o armazenamento a $7^{\circ} \mathrm{C}$ e $30^{\circ} \mathrm{C}$.

O teor de vitamina C (Figura 9) apresentou comportamento quadrático, tendendo a aumentar até o $10^{\circ}$ dia de armazenamento, onde foram registrados teores de 19,43 e $19,10 \%$ para os frutos acondicionados a $7^{\circ} \mathrm{C}$ e $30^{\circ} \mathrm{C}$, respectivamente, os quais ao término do período de armazenamento foram reduzidos a 9,72 e 10,49\%.

Figura 9 - Teor de Vitamina C (mg/100g) de maçãs com e sem a aplicação de revestimentos durante o armazenamento a temperatura refrigerada (a) e a temperatura ambiente (b).
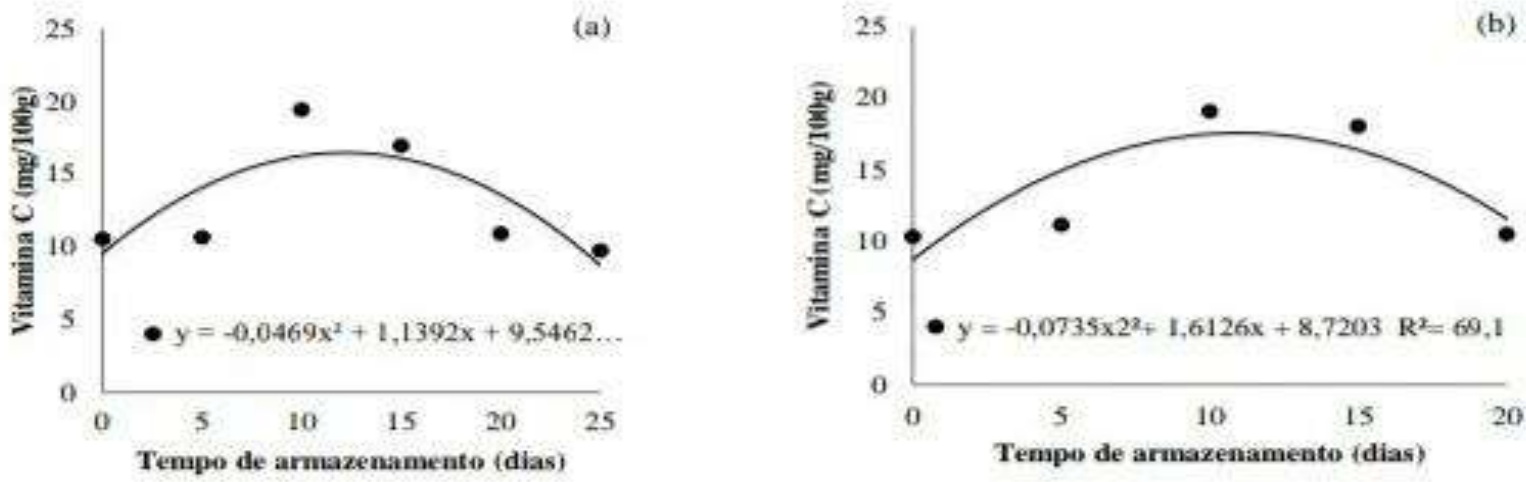

Fonte: Autores.

\section{Conclusão}

Os revestimentos de extrato de própolis vermelha foram eficientes, evitando o desenvolvimento de microorganismos, com ação mais eficaz na concentração com $5 \%$ em ambos ambientes, havendo também uma interação do Ratio, que significa que o fruto está em um ótimo grau de maturação, os outros parâmetros apresentaram valores equivalentes.

\section{Referências}

Assis, O. B. G. (2011). Características físico-químicas de coberturas comestíveis sobre frutas e hortaliças. Jornadas internacionais sobre avanço da tecnologia de filmes e coberturas funcionais em alimentos, 3.; Jornada da agrobio envases, 3. Campinas, 20-21.

Batista, A.G. B., Oliveira, B.D., Oliveira, M. A., Guedes, T. J. G., Silva, D. F., \& Pinto N. A. V. D. (2013). Parâmetros de qualidade de polpas de frutas congeladas: uma abordagem para produção do agronegócio familiar no Alto Vale do Jequitinhonha. Tecnologia e Ciência Agropecuária, 7(4), 49-54.

Brasil, Ministério da Saúde. Agência de Vigilância Sanitária (ANVISA). Resolução- RDC nº 12, de 2 de janeiro de 2001: regulamento técnico sobre padrões microbiológicos para alimentos.

Cabral, I. S. R., Oldoni, T. L. C., Prado, A., Bezerra, R. M. N., \& Alencar, S. M. (2009) Composição fenólica, atividade antibacteriana e antioxidante da própolis vermelha brasileira. Química Nova, 1-5.

Daugsch, A. A. (2007). Própolis vermelha do nordeste do Brasil e suas características químicas e biológicas. Tese (Doutorado em Ciência de Alimentos) Universidade Estadual de Campinas - Faculdade de Engenharia de Alimentos, São Paulo.

Davanço, T., Tanada-Palmu, P., \& Grosso, C. (2007). Filmes compostos de gelatina, triacetina, ácido esteárico ou capróico: efeito do pH e da adição de sufactantes sobre a funcionalidade dos filmes. Ciência e Tecnologia de Alimentos, Campinas, 27 (2), 408-419.

Food and Drug Administration - FAD. Generally recognized as safe (GRAS). (2013). Silver Spring.

Henrique, C. M., Cereda, M. P., \& Sarmento, S. B. S. (2008). Características físicas de filmes biodegradáveis produzidos a partir de amidos modificados de mandioca. Ciência e Tecnologia de Alimentos, Campinas, 28 (1) 231-240.

International Commission of Microbiological Specifications for Foods (ICMSF). (1978). Microorganisms in foods 1: their significance and methods of enumeracion. Toronto: University of Toronto Press, 2.ed., 434. 
Oliveira, B. S., \& Nunes, M. L. (2011). Avaliação de quitosana de caranguejo-uçá (Ucides cordatus) como biofilme protetor em caju. Scientia Plena, Aracaju, 7(4), 01-06.

Pastor, C., Sánchez-González, L., Cháfer, M., Chiralt, M., \& González- Martínez, S. (2010). Physical and antifungal properties of hydroxypropylmethylcellulose based films containing propolis as affected by moisture content. Carbohydrate Polymers, 82, 1174-1183.

Rojas-Graü, M. A., Tapia, M. S., Rodríguez, F. J., Carmona, A. J., Martin-Belloso, O. Alginate and gellan-based edible coatings as carriers of antibrowning agents applied on fresh-cut Fuji apples. Food Hydrocolloids. Amsterdam, 21(1), 118-127, 2007. http://dx.doi.org/10.1016/j.foodhyd.2006.03.001

Sánchez-González, L., Cháfer, M., Hernández, M., Chiralt, A., \& González-Martínez, C. (2011). Antimicrobial activity of polysaccharide films containing essential oils. Food Control, Oxford, 22 (8), 1302-1310.

Santos, Y. T. O. (2007). Qualidade sanitária de hortaliças cultivadas em um distrito sanitário de Salvador-BA e eficiência de soluções antimicrobianas sobre linhagens de Escherichia coli. [Dissertação]. Salvador: Universidade Federal da Bahia.

Souza, F. G., \& CÓL, C. D. (2014). Elaboração, qualidade físicoquímica, microbiológica e sensorial da salada de frutas em calda. Revista Brasileira de Produtos Agroindustriais, 16 (3), 313-317. 